\title{
Body representation in anorexia nervosa
}

Anouk Keizer \& Manja Engel

To appear in: The Routledge Handbook of Bodily Awareness. Alsmith, A. J. T. \& Longo, M. (eds.). New York: Routledge.

\section{Abstract}

Anorexia nervosa (AN) is an eating disorder that mainly affects young women. One of the most striking symptoms of this disorder is the distorted experience of body size and shape. Patients are by definition underweight, but experience and perceive their body as bigger than it in reality is. This body representation disturbance has fascinated scientists for many decades, leading to a rich and diverse body of literature on this topic. Research shows that AN patients do not only think that their body is bigger than reality, and visually perceive it as such, but that other sensory modalities also play an important role in oversized body experiences. Patients for example have an altered (enlarged) size perception of tactile stimuli, and move their body as if it is larger than it actually is. Moreover, patients with AN appear to process and integrate multisensory information differently than healthy individuals, especially in relation to body size. This leads to the conclusion that the representation of the size of the body in the brain is enlarged. This conclusion has important implications for the treatment of body representation disturbances in AN. Traditionally, treatment of AN is very cognitive in nature, it is possible however that changed cognitions with respect to body size experiences do not lead to actual changes in metric representations of body size stored in the brain. Recently, a few studies have been published in which a multisensory approach in treatment of body representation disturbance in AN has been found to be effective in treating this symptom of AN. 


\section{Introduction}

Humans' perception of the world is a curious phenomenon that has interested scholars as well as the general public for many decades. In the late 1800s, ambiguous figures such as Jastrow's Rabbit-Duck illusion (1899), depicting a drawing that can either be interpreted as a duck or a rabbit gained popularity. New visual illusions continued to emerge, just a few years ago a photograph of a dress (Hugrass et al., 2017) resulted in a heated debate on the internet: Some swore the color of the dress was black and blue, while others were certain that it was white and gold. Both examples illustrate that perception is a subjective process which shapes our individual reality. For example, person A might perceive a rabbit in Jastrow's Rabbit-Duck illusion, and person B might perceive a duck. Although both individuals perceive different animals, their perception is not inaccurate; it is their reality. Moreover, our reality seems flexible and can change from time to time: One might see a rabbit at first and a duck just a moment later.

Although these examples have served as food for scholars (Meng and Tong, 2004, Kornmeier and Bach, 2012, Rock and Mitchener, 1992, Lafer-Sousa et al., 2015, Hugrass et al., 2017) and at the same time have a high entertainment value, matters become more serious when an individual's subjective perception of reality can drive them toward behaviors with a life threatening outcome. The most striking illustration hereof can be observed in individuals suffering from anorexia nervosa (AN). AN patients typically have a very thin body, but they experience their body as bigger than its objective physical size (APA, 2013). For individuals suffering from AN, having an overweight body is their reality, which has serious consequences.

This chapter will provide a brief overview of research to body size experiences in AN. We first give an overview of the classic to recent work on body size experiences in AN. We continue this chapter by linking these scientific insights into body size experiences in AN to recent advances in the treatment of $A N$.

\section{Anorexia Nervosa}

AN is characterized by restricted food intake, which typically results in a low body weight. Despite a low body weight, patients have a strong fear of becoming fat or gaining weight. Another central symptom of AN is a distorted experience of the own body size, shape, and weight (APA, 2013). This is often referred to as a body image disturbance or disturbance in body representation. The disturbed way in which AN patients perceive and experience their body size has been linked to a worse prognosis (Calugi and Dalle Grave, 2019, Junne et al., 2019) and higher levels of relapse (Carter et al., 2004), making this a central characteristic of AN.

AN is an eating disorder that has an incidence of about 7.4 to 7.7 per 100,000 and typically affects young females, in which the incidence lies around 109.2 per 100,000 (van Son et al., 2006). The 
prevalence of $A N$ in men is about 10 times lower than in females (Raevuori et al., 2014). The prognosis of the disorder is rather poor (Khalsa et al., 2017), with only about $46 \%$ to $51 \%$ of patients fully recovering (Steinhausen, 2002, Lowe et al., 2001). About 31\% of the patients relapse after recovery (Berends et al., 2018) and 20\% remain chronically ill (Steinhausen, 2002). Estimates of mortality range from 5\% to 18\% (Arcelus et al., 2011, Harris and Barraclough, 1998, Sullivan, 1995, Lowe et al., 2001), putting AN among the psychiatric conditions with the highest mortality rate. Even though AN patients are often aware of the poor prognosis of the disorder and the dangers of being underweight in general, they rarely acknowledge the harmful effects of their condition, or the irrationality of their fear to gain weight.

'Because you have to be really thin to die, and I'm fat so it won't happen to me' (Tan, Hope, Steward and Fitzpatric 2006, p7.)

\section{Research on body image disturbance in AN}

\subsection{The classic view}

In the 1960s psychologists and psychiatrists gained an interest in understanding body image disturbance in AN. In one of the first papers on the topic, Hilde Bruch (1962), described body image in $\mathrm{AN}$ as a conceptual and perceptual disturbance. Distinguishing between cognitive affective and perceptual aspects of body image became common in the years following the paper by Bruch (1962) resulting in a large body of literature focusing on, for example, negative attitudes toward the body (Garner et al., 1984, Cash and Brown, 1987), altered perception of body size (Slade and Russell, 1973, Pierloot and Houben, 1978, Slade, 1985), or a combination of these two (Probst et al., 1990, Garner and Garfinkel, 1981). Perceptual aspects of body image were mainly studied in relation to visual perception of body size using Body Size Estimation (BSE) tasks during this time. Results of these studies typically indicated overestimation of body size by AN patients (see, e.g., Cash and Deagle, 1997, Smeets et al., 1997).

Several methodological and theoretical issues resulted in stagnation of the field in the $1990 \mathrm{~s}$ (Smeets, 1997, Smeets, 1995, Ben-Tovim et al., 1990). In perceptual psychology and psychophysics, the visual sense is dominant. A heavy focus on visual perception of body size is understandable, as it fits with clinical and anecdotal accounts of AN patients describing their disturbed body size experiences. Patients however, also report that their disturbed body image of "feeling fat" is something they feel from and within their body, rather than only thoughts they have or a reflection they see in the mirror (Espeset et al., 2011), as one patients states:

I feel like I'm too big and ungainly and just like I'm splurging out my clothes and I feel it all over my body. I just feel really, really crap.- (Major, 2016, p 51) 
A heavy focus on the visual sense, especially when studying body image in AN may be problematic. For AN patients, the body is not a neutral object but a very negatively valanced and salient concept. AN patients only show overestimations in the judgment of their own body size, but not when they estimate the size of objects or bodies of others (Bowden et al., 1989, Engel et al., 2020, Slade and Russell, 1973, Smeets et al., 1999). In addition, researchers came to the realization that performance on traditional body size estimation tasks may not only reflect the visual (mental) image of the body, but could be influenced by (negative) emotions concerning the body as well (Cash and Deagle, 1997, Smeets et al., 1997, Skrzypek et al., 2001, Farrell et al., 2005, Ben-Tovim et al., 1990). This called for a reconceptualization of the construct of body image (Smeets, 1997).

\subsection{Cognitive neuroscience view}

In the 2000s, researchers with a background in neuropsychology and cognitive neuroscience started gaining an interest in body image disturbances in AN (Wagner et al., 2003, Fassino et al., 2004, Grunwald et al., 2001, Grunwald et al., 2002), which resulted in advances in the field. The term body image disturbance was reconceptualized. The body image disturbance in AN was previously defined as patients holding negative attitudes about their body and judging their bodily appearance as fatter than it actually is (Smeets, 1995). In other words, it was assumed that AN patients literally held a fat mental image of their body and experienced negative emotions with respect to their body. The cognitive neuroscientific viewpoint offered opportunities for broadening this definition beyond how patients with AN think about their body and see their body. In cognitive neuroscience the umbrella term body representation refers not only to cognitive emotional experiences of the body, and visual perception of the body, but also includes bodily experiences derived from or influenced by other sensory modalities, such as touch or proprioception (see e.g. Longo, 2015, Longo and Haggard, 2010, Longo and Haggard, 2012, de Vignemont, 2010). This approach is more coherent and holistic than the traditional view on body image in AN. Cognitive neuroscientific theories of body representation align better with how the symptom of distorted body size experience presents itself clinically. AN patients report that indeed, they have negative thoughts about their body, visually perceive their body as bigger than it objectively is, but they also describe a more fundamental sensation of having a fat body - that, for example, includes being able to feel fat on their body.

In the field of cognitive neuroscience and neuropsychology, the underlying assumption seems to be that the brain continuously receives body-related input from different sensory modalities. This information can be related to how the body looks, but also related to where the body is located in space or how and where the skin is touched. The brain is thought to process this primarily multimodal information and integrate it into a coherent and abstract representation of the body (Dijkerman and de Haan, 2007, see e.g. de Vignemont, 2010, Serino and Haggard, 2010, Gallagher, 2005, Paillard, 1999, 
Haggard and Wolpert, 2005, Longo, 2015, Longo and Haggard, 2012). This body representation is assumed to store different kinds of bodily information from multiple senses. It is deemed crucial in a wide range of processes and behaviors, for example recognizing the own body, bodily semantics, identifying bodily threats, performing motor-sequences, tool-use, identifying the affective state the body is in. As such, the body representation plays a key role in an individuals' sense of ownership and agency over the own body, which is crucial in forming a sense of "being yourself" as well as being able to perform (goal-directed) behaviors (e.g. de Vignemont, 2010).

In neuropsychological and cognitive neuroscientific literature considerable debate exists on the number of representations of the body in the brain, the exact function(s) of each representation, and the basis on which they should be distinguished (see e.g. Dijkerman and de Haan, 2007, de Vignemont, 2010, Schwoebel and Coslett, 2005, Gallagher, 2005, Paillard, 1999, Haggard and Wolpert, 2005, Pitron et al., 2018, de Haan and Dijkerman, 2020, Longo, 2015, Longo and Haggard, 2012). An elaborate discussion of this debate is beyond the scope of this chapter. Some level of consensus exists with respect to the idea that the type of body representation that is activated, or the information that is retrieved from a body representation, is context or task dependent (see e.g. de Vignemont, 2010). In certain situations metric information on the location of the body in space may be especially relevant (e.g. when navigating a crowded hallway to reach the lab in which you will take part in an experiment), while on other instances this information is less crucial (e.g. when reporting whether you were touched on your left or right hand by an experimenter).

The conceptual discussion in the literature of the number of body representations has not withheld researchers to investigate body representations and potential disturbances in body representation in AN patients (Gaudio et al., 2014). For the majority of the studies the general assumption appears to be that AN patients overestimate their own body size. This is shown in studies focusing on metric representation (size of specific body parts) and depictive representation (whole body size) (Molbert et al., 2017a). This has been investigated in a variety of ways and considerable evidence for this hypothesis has been found.

\section{Body representation disturbances in AN}

\subsection{Visual body representation}

A great deal of work has been done focusing on the visual representation of the body. Several studies have found that in a variety of experimental paradigms AN patients overestimate the size of their body (for reviews see e.g. Molbert et al., 2017a, Gardner and Brown, 2014), but not of inanimate objects (Bowden et al., 1989, Slade and Russell, 1973, Engel et al., 2020) or the bodies of others (Smeets et al., 1999), ruling out a general deficit in visual perception and pleading in favor of visual representations of the own body being distorted in AN. 
Classical visual body size estimation tasks typically consist of drawings or images of different body types, ranging from underweight to overweight. The participant is asked to select the body that best represents their own body size. These classical tasks have been criticized since the body size estimates resulting from it are not necessarily a reflection of how the participant visually perceives their own body or of the visual mental representation of the size of the body. It cannot be ruled out that responses are potentially biased by, for example, negative body attitudes. To illustrate this, in a classical visual body size estimation task AN patients might provide their response based on making a comparison between the bodies depicted in the task and the visual mental image of their own body in their minds. However, we cannot rule out that, when AN patients are confronted with a body size estimation task they might provide their response by selecting the depicted body that best matches the attitude they have about their body (i.e., "My body is fat"). In the latter case, overestimation of body size would thus not be a reflection of an enlarged visual mental representation of the size in the body stored in the brain.

Another issue with classical visual body size estimation tasks is that they mostly made use of 2D images, while a 2D image does not reflect the volumetric properties of an actual human body. In response to this, new tasks were developed, taking advantage of recent technological developments. In stead of using static 2D images of bodies in body size estimation tasks, researchers have created detailed avatars of which body shape and weight can be manipulated in a very realistic way using 3D software and VR technology (see e.g. Cornelissen et al., 2017). Although these studies report overestimation of body size by AN patients (Cornelissen et al., 2017), some authors using these paradigms highlight that, similar to classical body size estimation tasks, negative body attitudes might drive such findings instead of a disturbance in the metric information derived from the body representation (Molbert et al., 2017b). Fisher and colleagues (2020) directly compared body size estimation assessed with a classical paper and pencil figure rating task to an innovative VR approach. They conclude that the extent to which AN patients overestimate body size does not differ between classical and more technologically advanced tasks. Although they are in favor of using biometrically enhanced experimental paradigms, this still does not seem to rule out potential methodological issues.

In order to bypass the confounding factors such as bodily attitudes while measuring visual body representation, other approaches, not involving the presentation of visual stimuli to participants, have been used. The reasoning behind this was that, when AN patients are not confronted with visual stimuli depicting a body, they might access their visual mental representation of body size instead of simply choosing the stimulus that best reflects their attitude of their body. An example of such an experimental task is a kinesthetic body size estimation task in which participants are blindfolded and estimate the width of parts of their body by moving the handles on a bar to match their body width (Lautenbacher et al., 1993). Another example is a mental distance comparison task. Here participants 
are instructed to mentally scan distances between different body parts and make rapid comparisons between them (e.g., Which distance is longer? From your left to your right shoulder or from your left to your right hip?) (Smeets et al., 2009, Keizer et al., 2011). Although such techniques do indeed not involve visual stimuli of bodies, there was no way to ascertain that participants indeed accessed their visual mental body size representation, making it difficult to rule out potential influences of body attitudes on task performance.

In short, AN patients seem to overestimate their visual mental representation of the size of their body but the tasks used are not without methodological flaws. There have been many attempts to control for methodological issues. However, as yet, none of those attempts have found a way to purely measure the visual body representation in AN. For a full discussion on methodological issues when measuring visual representation in AN see Gadsy (under review).

\subsection{Tactile body representation}

Another avenue that has been explored with respect to disturbances in metric body size representations is how these may be reflected in tactile perception. In some instances adequate tactile perception requires a representation of the size of the body. Upon touch mechanoreceptors convey afferent signals to the somatosensory cortex. In some situations, processing of tactile information by the somatosensory cortex is sufficient (see e.g. Dijkerman and de Haan, 2007), for example when asked to detect pressure provided by a single tactile stimulus. However, when for example asked to estimate the distance between two tactile pressure stimuli, processing by the somatosensory cortex does not suffice and additional rescaling is required (see e.g. Longo et al., 2010). In this rescaling process information from distorted somatotopic maps in the somatosensory cortex is mapped onto a metric representation of the physical size of the touched body part (Taylor-Clarke et al., 2004).

If the metric representation of the body part that is touched is disturbed, this could result in abnormal performance with respect to, e.g., estimating the distance between two tactile stimuli presented on the skin. This is what has been reported by several researchers who assessed tactile distance perception in AN. It was found that AN patients overestimate the distance between two tactile stimuli when asked to estimate this distance using their thumb and index finger while blindfolded (Keizer et al., 2011). Moreover, overestimation was most pronounced for body parts that were emotionally salient and typically also more overrepresented body parts, e.g., in patient reports (i.e., the abdomen, and thigh compared to the forearm and sternum; Keizer et al., 2012, Spitoni et al., 2015). In addition it was found that AN patients typically overestimate the distance between two tactile stimuli only when these are presented in the horizontal plane, compared to the vertical plane (Spitoni et al., 2015). It has been suggested that this supports the notion that the disturbance in metric 
body representation in AN takes the form of an overweight body, that is wider, especially in areas emotionally salient for AN patients, but not enlarged (or longer) in general (Gadsby, 2017b).

\subsection{Affordance perception}

Metrics of body size stored in body representation have also been assessed by examining motor planning and bodily action. A large body of literature exists on affordance perception in healthy individuals (see e.g. Warren and Whang, 1987, Wilmut and Barnett, 2010). In order to navigate our body safely through crowded spaces or cluttered environments it is crucial that our brain has access to up to date information on the location of our body in space, the position of our body and its parts relative to potential obstacles in our environment, and to a highly accurate metric representation of the size of our body. This is crucial for determining which actions the body affords given its size. Generally healthy individuals are well able to move around seemingly effortlessly in the external world without continually bumping into obstacles or knocking things over. Experimental work has shown that healthy individuals are able to quickly recalibrate affordance perception when faced with changes in bodily dimensions (e.g. due to wearing a backpack, holding a long rod, or sitting in a wheelchair; see e.g. Yasuda et al., 2014, Franchak, 2017, Franchak and Somoano, 2018). This implicates that the metric representation of body size that we use for determining which actions we can perform given the size of our body is dynamic and can (and need to) be quickly updated.

A commonly used experimental paradigm for assessing affordance perception includes a task in which participants are asked to walk through an aperture. This doorway like opening can be adjusted in width across trials, which allow for determining the critical aperture to shoulder ratio (Warren and Whang, 1987). In AN patients these paradigms have been used as well, showing that AN patients' critical aperture to shoulder ratio is significantly larger than that of healthy controls (Keizer et al., 2013, Metral et al., 2014). In other words, AN patients rotated their shoulders beyond natural sway for apertures that they could have easily walked thourgh without adjusting their body posture. Abnormal affordance perception in AN was not only found for bodily action tasks, but also for motor imagery tasks, in which participants were asked to imagine walking through an aperture (Metral et al., 2014, Guardia et al., 2012, Guardia et al., 2010). These findings provide further evidence for the hypothesis that metric information in body representation is distorted in AN patients. Interestingly, the increased critical aperture to shoulder ratio in AN patients was not found to be related to their BMI before the onset of AN, which argues against the possibility that AN patients' body representation was simple never updated when weight loss occurred in the acute phase of the illness (Metral et al., 2014). Moreover, when the critical aperture to shoulder ratio was calculated using shoulder width that participants estimated to have in a BSE task instead of their actual shoulder width, differences between AN patients and healthy controls were no longer significant (Keizer et al., 2013). Taken together, these 
findings suggest that the metric information in the implicit representation of the body that is thought to play a crucial role in bodily action (see e.g. de Vignemont, 2010) is inaccurate (enlarged) in AN, resulting in AN patients moving their body in space as if it is larger than their actual physical dimensions.

\subsection{Multisensory body illusions}

Even though the disturbed experience of body size in AN patients can be quantified with a variety of different paradigms, work with multisensory body illusions has shown that metric aspects of AN patients' body representation are flexible and can (temporarily) be changed. Bodily illusions that have been studied in AN patients are for example, the rubber-hand illusion (RHI) and the full-body illusion. In the RHI (see e.g. Botvinick and Cohen, 1998, Kammers et al., 2009, Ehrsson et al., 2004) participants typically view a fake rubber hand lying in front of them in an anatomically correction position while their real hand is occluded from view. The experimenter strokes the rubber hand and real hand synchronously, which leads to visiotactile integration and gives rise to the experience of the rubber hand belonging to the own body ("I see a hand in front of me being touched and simultaneously feel this touch on my skin; therefore the hand that is in directly in front of me must be my own hand"). Often an asynchronous control condition is included in RHI experiments as well, in which stroking of the rubber hand and real hand is alternated. Since there is no temporal match between visual and tactile input in the asynchronous condition, visuotactile integration is absent or significantly reduced and participants do not have a (strong) experience of the rubber hand being part of the own body. Along the lines of the $\mathrm{RHI}$ other body illusions have been developed as well, in which participants experience ownership over an entire fake body, as if they have swapped bodies with an another individual or avatar (see e.g. Banakou et al., 2013, Peck et al., 2013, Slater et al., 2010, Petkova and Ehrsson, 2008, Preston and Ehrsson, 2014). In a full body illusion participants typically see the body of a 3D avatar of a prerecorded video of the body of another individual through a headmounted display. Similar to the RHI, an experience of ownership of this other body is induced by providing a temporal match between visuotactile information.

A greater susceptibility to the RHI in AN has, for example, been linked to a more malleable body representation in this group (Eshkevari et al., 2012, Eshkevari et al., 2014). In other words, AN patients seem more prone to easily accept false information on what belongs to their body and what does not belong to their body. This is not necessarily indicative of a distorted representation of the body or its size, but it does reflect a more instable body representation. A few studies have, in addition, directly assessed the effects of bodily illusions on the metric representation of body size by asking participants to estimate their body size after subjecting them to the illusion. The results of these studies do not allow for a straightforward conclusion. Some studies reported a more veridical body 
size estimation in AN patients after they completed a body illusion paradigm (Serino et al., 2019, Keizer et al., 2014, Keizer et al., 2016). However, changes in body size estimation occurred not only in the synchronous condition but also in the asynchronous condition, in which no illusionary ownership over a fake body (part) occurred (Keizer et al., 2014, Keizer et al., 2016). It appears that overestimation of body size in AN patients can be changed and as such is flexible, it is however questionable whether multisensory illusions could be a driving factor for this change. Although full-body illusions have been gaining popularity as novel treatment methods for the disturbed experience of body size in AN (PorrasGarcia et al., 2020), there is limited evidence that they actually succeed in altering the disturbed metric body representation that is typically observed in AN (Provenzano et al., 2019).

Taken together the work reviewed in this section shows that the disturbed perception and experience of body size in AN affects more sensory modalities than was generally assumed. Oversized experiences in AN are not limited to how AN patients think about their body or how they visually perceive their body. AN patients literally feel touch on their body as bigger than reality (see e.g. Spitoni et al., 2015, Keizer et al., 2012) and they even plan and execute motor actions as if their body is bigger than its objective physical dimensions (see e.g. Keizer et al., 2013, Guardia et al., 2010). Considerable evidence has thus accumulated in favor of the hypothesis that the disturbed experience of body size in AN is driven by or reflects a distorted body representation in which specifically metric information on body size is stored inaccurately (as fatter). Although a number of studies have shown that body size estimation can be changed to a more accurate size estimate (see e.g. Keizer et al., 2014, Keizer et al., 2016), it is unclear whether such improvements in body size estimation actually reflect a more veridical metric representation of body size. The new body of research on overestimation of metric body size in AN is interesting, as it helps to gain understanding of the puzzling concept of why AN patients feel fat. This has resulted in several relevant conceptual papers that provide theoretical models of what exactly the symptom of a disturbed experience of body size and shape entails and how it should be conceptualized (see e.g. Gadsby, 2017a, Gadsby, 2017b, Riva, 2016, Riva and Gaudio, 2018, Riva and Gaudio, 2012, Badoud and Tsakiris, 2017, Gadsby, 2017c). Apart from theoretical advances the question remains how we can use newly accumulated knowledge on body representation disturbances in AN to aid clinical practice.

\section{Implications for AN treatment}

\subsection{Treatment as usual}

It is important to stress here that, although this chapter focuses specifically on the distorted experience of body size in AN, this is just one of a few symptoms that constitute the disorder (APA, 2013). Body representation disturbances, together with the other symptoms, anxiety to gain weight and rigid eating behaviors, often put a lot of strain on the patients' quality of life and inflict high levels of 
functional impairment on patients and their carers (see e.g. Lowe et al., 2001, Treasure et al., 2012, Agh et al., 2016, DeJong et al., 2013). Over the years, several standardized treatments have been developed for AN, such as: enhanced cognitive behaviour therapy, family-based treatment, maudsley model of anorexia treatment, and specialist supportive clinical management (for a detailed overview see Zipfel et al., 2015). Although all these treatments are effective (but none is superior) in treating eating pathology in AN, AN remains hard to treat and full recovery is attained by barely half of the patients (see e.g. Steinhausen, 2002). Relapse, chronicity and mortality rates are relatively high (see e.g. Steinhausen, 2002, Lowe et al., 2001).

Standardized treatment for AN primarily focuses on weight restoration through nutrition assistance and/or challenging dysfunctional beliefs and learning functional coping strategies to deal with negative cognitions and affect (see e.g. Noordenbos and Elburg, 2018). Although standardized guidelines for treatment of AN exist, treatment approaches are quite heterogeneous. Some focus on maintaining factors of $\mathrm{AN}$, others on familydynamics, or certain AN-specific traits. It is beyond the scope of this chapter to discuss different treatment options in detail (but see e.g. Zipfel et al., 2015). For present purposes, we only focus on treatment for body image disorder.

The vast majority of standardized treatments for AN take a cognitive approach to treating the disorder. With respect to the disturbed experience of body size and shape this means that during treatment, patients are informed about their BMI (which is often underweight) to confront them with the fact that they are not fat. Although patients are generally capable of understanding that their BMI is too low for quantifying the experience of feeling fat, this cognitive process does not automatically lead to changes in metric and/or depictive aspects of body representation, or changes in processing of sensory information related to body metrics. In other words, during standardized treatment for eating disorders patients may be taught coping strategies that enable them to deal with feeling fat, but the sensory experience of body size not changed. Studies have shown that recovered AN patients still show body representation disturbances at a pathological level (see e.g. Engel and Keizer, 2017, Exterkate et al., 2009, Eshkevari et al., 2014). It was, for example, found that performance on a visual body size estimation task and affordance perception task, did not differ between currently ill AN patients and patients who had completed eating disorder treatment (Engel and Keizer, 2017). This implies that although eating disorder interventions can result in weight restoration and the ability to adhere to a healthy diet by changing maladaptive cognitions with respect to eating, they may not be very efficient in altering how body size and shape are experienced by patients.

\subsection{Benefits of a multimodal treatment approach}

The disturbed experience of body size and shape has been identified as a complicating factor in recovery of AN (see e.g. Junne et al., 2019). Clinical experience shows that AN patients often 
experience a discrepancy between what they know (e.g., "my BMI is too low; it is therefore impossible that I am fat") and their sensory bodily experiences (e.g., "every time I sit down I feel my thighs spreading out and fat rolls bulging over my jeans"). This makes it challenging and stressful for AN patients to gain weight during treatment, as one of our patients clearly states:

I feel bad about the mismatch between my feelings and my common sense. I would want to trust my feelings and I can't. Your senses can deceive you in many ways, it would be so nice if I could trust what I feel and that I could be ok with that feeling.

The problem (and possible solution) lies in the fact that the disturbed (enlarged) metric body representation needs to be updated. Such a change in body representation might not be accomplished with cognitive standardized treatments and may explain why patients who completed treatment do show improvements with respect to body attitudes, but still perform similar to acute AN patients on tasks assessing metric aspects of body representation (Engel and Keizer, 2017). Updating of body representations is a process that is common in healthy adults, and even crucial for an uncomplicated interaction with the environment. The metric representation of body size can be updated via feedback through sensory experiences. Pregnancy provides a clear illustration of this process. As the belly of the prospective mother grows, she might encounter situations in which her affordance perception needs to be adjusted. In some cases she might collide with objects in her environment, which provides a direct feedback signal for the brain about the new physical dimensions of the body. Based on this information metric information in the body representation can be updated so that future collisions are prevented. Not only prospective mothers possess this skill (Franchak and Adolph, 2014). Several studies report that when bodily dimensions of healthy participants are altered (e.g., by asking them to wear a large backpack) the brain quickly adjusts to these new dimensions and that feedback - through, for example, collisions - plays a crucial role in this (see e.g. Franchak, 2017, Franchak et al., 2012, Franchak and Somoano, 2018, Yasuda et al., 2014). Over the course of a single experimental session it is possible to (temporarily) update the metric representation of body size which shows from accurate affordance perception at the end of the experiment. These results seem to suggest that it is possible to at least temporarily update the metric representation of body size that is needed for accurate affordance perception. However, it should be noted that it is not yet clear if wearing, for example a large backpack actually changes (enlarges) the representation of body size, or whether the backpack is temporarily "added" to the body representation, like a tool (see also Ishibashi et al., 2000).

In AN patients, the problem is that they operate from an enlarged metric body representation. Patients, for example, move through apertures as though they are larger than their actual physical 
dimensions (see e.g. Keizer et al., 2013, Metral et al., 2014). This actually prevents them from colliding with objects in the external environment. As such, AN patients are less likely to encounter situations in which their inaccurate representation of body size is challenged through direct sensory feedback. An important function of (metric) body representations might be that it ensures that bodily integrity is maintained by keeping the body safe from harm. Indeed, in affordance perception literature a "safety margin" is often observed in healthy individuals (Warren and Whang, 1987, Wilmut and Barnett, 2010). "Better safe than sorry" seems to apply here. In the case of AN, of whom it could be said that they hold an extreme safety margin (see e.g. Metral et al., 2014, Guardia et al., 2010, Nico et al., 2010), the need for updating the metric body representation might be more or less absent: Although their metric representation of body size is enlarged, this does not inflict immediate harm to their body in terms of collisions with objects or other individuals.

Clinical examples of affordance perception in AN patients are characterized by automatic avoidance of feedback opportunities. An anecdotal report, for example, is that AN patients prefer to remain standing when they take the bus, as they judge the space next to another passenger as too small for them to fit in. Affordance perception is a relatively implicit process and as such the option "taking a seat" might not even be consciously processed and continuously reviewing all the behavioural options that your body does not afford given its size would be maladaptive and interfere with daily functioning.

Taken together, the urgency for updating the metric body representation in AN might be low, as no apparent physical harm is caused by having an enlarged representation of body size. AN patients might simply have fewer opportunities than healthy individuals for updating their metric body representation through sensory feedback. Following this line of reasoning a therapeutic intervention for the disturbed experience of body size in AN that focuses on challenging the enlarged metric body representation by creating (multisensory) feedback opportunities might be promising.

\subsection{Recent advances in treatment of body representation disturbances}

Over the past years a few novel therapeutic approaches have been developed that specifically target the disturbed experience of body size and shape in AN while taking a multisensory approach. We will discuss two examples of such approaches of which the effectiveness has been reported in the literature.

One approach is based on the concentrative movement therapy (CMT). This is a bodypsychotherapeutic approach that is adapted to the needs of AN patients (CMT; www.dakbt.de). This treatment consists of several phases. In the first phase AN patients are encouraged to engage in experiencing bodily signals by performing conscious tactile, proprioceptive and interoceptive exercises. In the second phase patients are challenged to integrate these perceptual experiences with 
cognitive-affective representations of their body and self. Moreover, patients are encouraged to share bodily experiences with others (Dalhoff et al., 2019). The underlying assumption of this treatment approach is that by performing a variety of body focused exercises consciously and attentively this will result in experiences that facilitate updating of the metric representation of the size of the body. A recent study investigated the effectiveness of this intervention in a group of adolescent AN patients. Results showed that indeed overestimations in a visual body size estimation task was reduced for emotionally salient body parts such as the waist and thighs (Dalhoff et al., 2019).

Another multimodal approach is hoop training (www.hoepeltraining.nl; Keizer et al., 2019). Hoop training consists of eight individual sessions. The primary focus of this psychomotor intervention is providing AN patients with direct feedback on their body size through various senses. This is accomplished by confronting patients with a series of different-sized hoops that are lined up in front of them. Patients are instructed to choose from this series of hoops the hoop that perfectly fits around their body. In each session patients are asked to step inside the hoop of their choice and lift it up over their head. In the first few sessions patients often choose a hoop that is much larger than their actual circumference. The therapist coaches the patient and challenges them to choose more realistically in subsequent sessions by, for example, asking what it means that the hoop they chose did not touch their hips or other parts of their body when they moved through it.

An advantage of hoop training is that it addresses bodily experiences in multiple modality simultaneously. Patients visually perceive hoops lying in front of them, which triggers cognitions about their body size in relation to these hoops, moreover, patients actually move their body through the hoops and feel the hoops touching their body. Over the course of treatment most patients are able to match their body size to one of the hoops lined up in front of them. Hoop training seems effective in updating the metric body representation. In a study measuring the effectiveness of hoop training, a group of AN patients who completed standardized psychomotor treatment for disturbed body size experiences was compared to a group of AN patients who completed standardized psychomotor treatment and hoop training. Results indicated that both groups showed improvements in bodily attitudes and that neither group showed improvements on a visual body size estimation task. Interestingly, Hoop training appeared to selectively improve tactile size estimation and affordance perception, as the group that completed hoop training showed greater improvements in both tasks assessing this than the group that completed standardized treatment (Keizer et al., 2019).

It thus seems that both hoop training and CMT, in which a multimodal instead of cognitive approach is taken, have beneficial effects on disturbances in the metric representation of body size in AN patients. It should be noted, though, that neither hoop training nor CMT are intended to replace existing treatments for AN altoghether, but they are complementary to existing treatments. Both interventions do seem to be promising treatment approaches in which sensory experiences of body 
size are central. Especially hoop training clearly offers opportunities for direct feedback on body size and at the same time challenges the enlarged metric representation of body size, as patients over the course of treatment engage in behavior (i.e. moving through a tightly fitting hoop) that they are unlikely to encounter in daily life. The initial results with regard to the effectiveness of hoop training and CMT are promising (Keizer et al., 2019); however, long-term follow-up research tracking AN patients over the course of several months is needed before firm conclusions can be drawn.

\section{Challenges for future research}

In this chapter we have reviewed a small part of the great number of studies that have been conducted over the past sixty years, to deepen our understanding of body representation disturbances in AN. Although some of these findings have found their way to clinical practice in the form of novel treatment approaches, some challenges for researchers still lie ahead.

In the 1990s a major issue that researchers kept encountering, is that it was unclear how to disentangle cognitive-attitudinal and perceptual disturbances in body representation (Smeets, 1997, Ben-Tovim et al., 1990). The body of work discussed here focused primarily on how altered performance on a variety of tasks related to body perception and action could be indicative of an enlarged metric representation of body size. In this work there has been relatively little attention for potential influences of cognitive processes related to the experience of negative emotions about the body, such as stress or anxiety, that might influence the perceptual estimate. This is remarkable, as anecdotal clinical reports illustrate that in AN disturbed experiences of body size and shape are not neutral, but often accompanied by negative emotions. A question that comes to mind is, is it realistic to investigate body size estimation in AN without taking into account that for AN patients the body is a stressful and anxiety provoking construct? It was recently found that in AN patients a significant increase in state anxiety co-occurred with completing different body size estimation paradigms (Hasenack et al., 2021). A hypothesis resulting from this study is that part of the overestimation of body size typically found in AN may potentially be caused by patients finding the experimental setting (completing a body size estimation task) very distressing. This hypothesis needs to be addressed in future research. Of note, we do know that individuals tend to overestimate the size of phobic objects (Vasey et al., 2012, Teachman et al., 2008, Stefanucci et al., 2008). For example, overestimation of a vertical distance increased as fear of heights increased (Clerkin et al., 2009).

While the above poses a new challenge to be addressed in future work, a challenge that remains is the role of attitudes about the body (i.e. the persistent thought that "I am fat") in oversized experiences in AN patients. Some researchers even claim that overestimation of body size in visual body size estimation tasks is mainly driven by attitudinal factors (see e.g. Molbert et al., 2017b). In 
addition, it has been found, for example, that AN patients' altered tactile perception is most pronounced in body parts that are emotionally salient (see e.g. Spitoni et al., 2015).

A recent study aimed to experimentally tease apart perceptional and attitudinal influences by manipulating the response time in tactile estimation judgments in AN patients. Results showed that, when AN patients were asked to make an immediate tactile judgment (leaving no time to reflect), they showed fewer overestimations, compared to when AN patients were given five seconds before making their judgment (Engel et al., 2021). This might indicate that perceptional estimates in body size estimation tasks reflect not only an unrealistic metric representation of body size, but also negative cognitive-affective processes.

Although a close connection between perceptual body size experiences and cognitive-affective processes might come natural to those who have interacted with AN patients, theoretically this connection is challenging. There is an ongoing debate on the penetrability of bodily perception by attitudinal factors (see e.g. Firestone and Scholl, 2016). It is beyond the scope of this chapter to resolve this discussion or provide an in-depth review of this discussion. However, it is important to note that when it comes to AN research we have moved forward significantly over the past sixty years, but we are not there yet: The need to provide an answer to the question "why do AN patients overestimate their body size?" remains.

\section{Conclusion}

Anorexia nervosa (AN) is an eating disorder that mainly affects young women. One of the most striking symptoms of this disorder is the distorted experience of body size and shape (APA, 2013). Patients are by definition underweight, but experience and perceive their body as bigger than it in reality is. This body representation disturbance has fascinated scientists for many decades, leading to a rich and diverse body of literature on this topic (see e.g. Bruch, 1962, Cash and Deagle, 1997, Smeets, 1997, Molbert et al., 2017a, Gaudio et al., 2014, Gardner and Brown, 2014, Gadsby, 2017a). Research has shown that AN patients do not only think that their body is bigger than it in reality is, and visually perceive it as such (see e.g. Cash and Deagle, 1997), but that other sensory modalities also play an important role in oversized body experiences. Patients for example have an altered (enlarged) size perception of tactile stimuli (see e.g. Keizer et al., 2011), and move their body as if it is larger than it actually is (see e.g. Metral et al., 2014). Moreover, patients with AN appear to process and integrate multisensory information differently than healthy individuals (see e.g. Eshkevari et al., 2012), especially in relation to body size. This leads to the conclusion that the representation of the size of the body in the brain is enlarged. This conclusion has important implications for the treatment of body representation disturbances in AN. Traditionally treatment of AN is very cognitive in nature, it is possible that changes cognitions with respect to body size experiences does not lead in actual changes 
in the metric representation of body size stored in the brain. When we again consider the examples of the ambiguous figure, or "the dress" from the introduction of this chapter, it might feel like an open door to accept that different people have a different reality. In other words, it comes as no surprise that someone who perceives the dress as white and gold will not experience a change in perception of color just because they are told that the dress is actually blue and black. This principle can and should be applied to patients with AN as well. We should not expect that their reality - i.e., their (distorted) perception of body size - will change simply because they are told that they are perceiving their body as bigger than it in reality is. The brain constructs a metric representation of the size of the body in the brain based on input from different sensory modalities (see e.g. de Vignemont, 2010). This metric representation of body size is fundamental to the percept and experience of the body and its size (see e.g. Longo, 2015, Longo et al., 2010). Changing the metric body representation and as such the percept and experience of body size will as such be most effective if in treatment approaches - more realistic - body size experiences are offered through several sensory modalities (Keizer et al., 2019, Dalhoff et al., 2019).

\section{References}

AGH, T., KOVACS, G., SUPINA, D., PAWASKAR, M., HERMAN, B. K., VOKO, Z. \& SHEEHAN, D. V. 2016. A systematic review of the health-related quality of life and economic burdens of anorexia nervosa, bulimia nervosa, and binge eating disorder. Eat Weight Disord, 21, 353-364.

APA 2013. Diagnostic and statistical manual of mental disorders, Washington, DC, Author.

ARCELUS, J., MITCHELL, A. J., WALES, J. \& NIELSEN, S. 2011. Mortality rates in patients with anorexia nervosa and other eating disorders. A meta-analysis of 36 studies. Archives of General Psychiatry, 68, 724-31.

BADOUD, D. \& TSAKIRIS, M. 2017. From the body's viscera to the body's image: Is there a link between interoception and body image concerns? Neurosci Biobehav Rev, 77, 237-246.

BANAKOU, D., GROTEN, R. \& SLATER, M. 2013. Illusory ownership of a virtual child body causes overestimation of object sizes and implicit attitude changes. Proc Natl Acad Sci U S A, 110, 12846-51.

BEN-TOVIM, D. I., WALKER, M. K., MURRAY, H. \& CHIN, G. 1990. Body size estimates: Body image or body attitude measures? International Journal of Eating Disorders, 9, 57-67.

BERENDS, T., BOONSTRA, N. \& VAN ELBURG, A. 2018. Relapse in anorexia nervosa: a systematic review and meta-analysis. Curr Opin Psychiatry, 31, 445-455.

BOTVINICK, M. \& COHEN, J. 1998. Rubber hands 'feel' touch that eyes see. Nature, 391, 756.

BOWDEN, P. K., TOUYZ, S. W., RODRIGUEZ, P. J., HENSLEY, R. \& BEUMONT, P. J. 1989. Distorting patient or distorting instrument? Body shape disturbance in patients with anorexia nervosa and bulimia. Br J Psychiatry, 155, 196-201.

BRUCH, H. 1962. Perceptual and Conceptual Disturbances in Anorexia-Nervosa. Psychosomatic Medicine, 24, 187-\&.

CALUGI, S. \& DALLE GRAVE, R. 2019. Body image concern and treatment outcomes in adolescents with anorexia nervosa. Int J Eat Disord, 52, 582-585.

CARTER, J. C., BLACKMORE, E., SUTANDAR-PINNOCK, K. \& WOODSIDE, D. B. 2004. Relapse in anorexia nervosa: a survival analysis. Psychol Med, 34, 671-9.

CASH, T. F. \& BROWN, T. A. 1987. Body image in anorexia nervosa and bulimia nervosa. A review of the literature. Behav Modif, 11, 487-521. 
CASH, T. F. \& DEAGLE, E. A., 3RD 1997. The nature and extent of body-image disturbances in anorexia nervosa and bulimia nervosa: a meta-analysis. Int J Eat Disord, 22, 107-25.

CLERKIN, E. M., CODY, M. W., STEFANUCCI, J. K., PROFFITT, D. R. \& TEACHMAN, B. A. 2009. Imagery and fear influence height perception. J Anxiety Disord, 23, 381-6.

CORNELISSEN, K. K., MCCARTY, K., CORNELISSEN, P. L. \& TOVEE, M. J. 2017. Body size estimation in women with anorexia nervosa and healthy controls using 3D avatars. Sci Rep, 7, 15773.

DALHOFF, A. W., ROMERO FRAUSTO, H., ROMER, G. \& WESSING, I. 2019. Perceptive Body Image Distortion in Adolescent Anorexia Nervosa: Changes After Treatment. Front Psychiatry, 10, 748.

DE HAAN, E. H. F. \& DIJKERMAN, H. C. 2020. Somatosensation in the Brain: A Theoretical Re-evaluation and a New Model. Trends Cogn Sci, 24, 529-541.

DE VIGNEMONT, F. 2010. Body schema and body image--pros and cons. Neuropsychologia, 48, 66980.

DEJONG, H., OLDERSHAW, A., STERNHEIM, L., SAMARAWICKREMA, N., KENYON, M. D., BROADBENT, H., LAVENDER, A., STARTUP, H., TREASURE, J. \& SCHMIDT, U. 2013. Quality of life in anorexia nervosa, bulimia nervosa and eating disorder not-otherwise-specified. J Eat Disord, 1, 43.

DIJKERMAN, H. C. \& DE HAAN, E. H. 2007. Somatosensory processes subserving perception and action. Behav Brain Sci, 30, 189-201; discussion 201-39.

EHRSSON, H. H., SPENCE, C. \& PASSINGHAM, R. E. 2004. That's my hand! Activity in premotor cortex reflects feeling of ownership of a limb. Science, 305, 875-7.

ENGEL, M. M., GADSBY, S., CORCORAN, A. W., KEIZER, A., DIJKERMAN, C. \& HOHWY, J. 2021. Waiting longer, feeling fatter: Effects of response delay on tactile distance estimation and confidence in females with anorexia nervosa. PsyArXiv Preprints.

ENGEL, M. M. \& KEIZER, A. 2017. Body representation disturbances in visual perception and affordance perception persist in eating disorder patients after completing treatment. Sci Rep, 7, 16184.

ENGEL, M. M., VAN DENDEREN, K., BAKKER, A. R., CORCORAN, A. W., KEIZER, A. \& DIJKERMAN, H. C. 2020. Anorexia nervosa and the size-weight illusion: No evidence of impaired visual-haptic object integration. PLoS One, 15, e0237421.

ESHKEVARI, E., RIEGER, E., LONGO, M. R., HAGGARD, P. \& TREASURE, J. 2012. Increased plasticity of the bodily self in eating disorders. Psychol Med, 42, 819-28.

ESHKEVARI, E., RIEGER, E., LONGO, M. R., HAGGARD, P. \& TREASURE, J. 2014. Persistent body image disturbance following recovery from eating disorders. Int J Eat Disord, 47, 400-9.

ESPESET, E. M., NORDBO, R. H., GULLIKSEN, K. S., SKARDERUD, F., GELLER, J. \& HOLTE, A. 2011. The concept of body image disturbance in anorexia nervosa: an empirical inquiry utilizing patients' subjective experiences. Eat Disord, 19, 175-93.

EXTERKATE, C. C., VRIESENDORP, P. F. \& DE JONG, C. A. 2009. Body attitudes in patients with eating disorders at presentation and completion of intensive outpatient day treatment. Eating Behaviors, 10, 16-21.

FARRELL, C., LEE, M. \& SHAFRAN, R. 2005. Assessment of body size estimation: a review. European Eating Disorders Review, 13, 75-88.

FASSINO, S., PIERO, A., GRAMAGLIA, C. \& ABBATE-DAGA, G. 2004. Clinical, psychopathological and personality correlates of interoceptive awareness in anorexia nervosa, bulimia nervosa and obesity. Psychopathology, 37, 168-74.

FIRESTONE, C. \& SCHOLL, B. J. 2016. Cognition does not affect perception: Evaluating the evidence for "top-down" effects. Behav Brain Sci, 39, e229.

FISHER, S., ABDULLAH, A., CHARVIN, I., DA FONSECA, D. \& BAT-PITAULT, F. 2020. Comparison of body image evaluation by virtual reality and paper-based figure rating scales in adolescents with anorexia nervosa: retrospective study. Eat Weight Disord, 25, 735-743.

FRANCHAK, J. M. 2017. Exploratory behaviors and recalibration: What processes are shared between functionally similar affordances? Atten Percept Psychophys, 79, 1816-1829.

FRANCHAK, J. M. \& ADOLPH, K. E. 2014. Gut estimates: Pregnant women adapt to changing possibilities for squeezing through doorways. Atten Percept Psychophys, 76, 460-72. 
FRANCHAK, J. M., CELANO, E. C. \& ADOLPH, K. E. 2012. Perception of passage through openings depends on the size of the body in motion. Exp Brain Res, 223, 301-10.

FRANCHAK, J. M. \& SOMOANO, F. A. 2018. Rate of recalibration to changing affordances for squeezing through doorways reveals the role of feedback. Exp Brain Res, 236, 1699-1711.

GADSBY, S. 2017a. Anorexia and oversized experiences. Philosophical Psychology, 30, 594-615.

GADSBY, S. 2017b. Distorted body representations in anorexia nervosa. Conscious Cogn, 51, 17-33.

GADSBY, S. 2017c. Explaining body size beliefs in anorexia. Cogn Neuropsychiatry, 22, 495-507.

GADSBY, S. under review. Visual self-misperception in eating disorders.

GALLAGHER, S. 2005. How the Body Shapes the Mind, Oxford, Oxford University Press.

GARDNER, R. M. \& BROWN, D. L. 2014. Body size estimation in anorexia nervosa: a brief review of findings from 2003 through 2013. Psychiatry Res, 219, 407-10.

GARNER, D. M. \& GARFINKEL, P. E. 1981. Body image in anorexia nervosa: measurement, theory and clinical implications. Int J Psychiatry Med, 11, 263-84.

GARNER, D. M., OLMSTED, M. P., POLIVY, J. \& GARFINKEL, P. E. 1984. Comparison between weightpreoccupied women and anorexia nervosa. Psychosom Med, 46, 255-66.

GAUDIO, S., BROOKS, S. J. \& RIVA, G. 2014. Nonvisual multisensory impairment of body perception in anorexia nervosa: a systematic review of neuropsychological studies. PLoS One, 9, e110087.

GRUNWALD, M., ETTRICH, C., ASSMANN, B., DAHNE, A., KRAUSE, W., BUSSE, F. \& GERTZ, H. J. 2001. Deficits in haptic perception and right parietal theta power changes in patients with anorexia nervosa before and after weight gain. Int J Eat Disord, 29, 417-28.

GRUNWALD, M., ETTRICH, C., BUSSE, F., ASSMANN, B., DAHNE, A. \& GERTZ, H. J. 2002. Angle paradigm: a new method to measure right parietal dysfunctions in anorexia nervosa. Arch Clin Neuropsychol, 17, 485-96.

GUARDIA, D., CONVERSY, L., JARDRI, R., LAFARGUE, G., THOMAS, P., DODIN, V., COTTENCIN, O. \& LUYAT, M. 2012. Imagining one's own and someone else's body actions: dissociation in anorexia nervosa. PLoS One, 7, e43241.

GUARDIA, D., LAFARGUE, G., THOMAS, P., DODIN, V., COTTENCIN, O. \& LUYAT, M. 2010. Anticipation of body-scaled action is modified in anorexia nervosa. Neuropsychologia, 48, 3961-6.

HAGGARD, P. \& WOLPERT, D. M. 2005. Disorders of body scheme. In: FREUND, H. J., JEANNEROD, M., HALLETT, M. \& LEGUARDA, R. (eds.) Higher-order motor disorders. Oxford: Oxford University Press.

HARRIS, E. C. \& BARRACLOUGH, B. 1998. Excess mortality of mental disorder. Br J Psychiatry, 173, $11-$ 53.

HASENACK, B., STERNHEIM, L., BIJSTERBOSCH, J. \& KEIZER, A. 2021. The link between anxiety and assessment of body attitudes and body size estimation in anorexia nervosa. Journal of Experimental Psychopathology, 12, 8.

HUGRASS, L., SLAVIKOVA, J., HORVAT, M., MUSAWI, A. A. \& CREWTHER, D. 2017. Temporal brightness illusion changes color perception of "the dress". J Vis, 17, 6.

ISHIBASHI, H., HIHARA, S. \& IRIKI, A. 2000. Acquisition and development of monkey tool-use: behavioral and kinematic analyses. Can J Physiol Pharmacol, 78, 958-66.

JASTROW, J. 1899. Duck-Rabbit Illusion. The mind's eye. Popular Science Monthly, 54, 299-312.

JUNNE, F., WILD, B., RESMARK, G., GIEL, K. E., TEUFEL, M., MARTUS, P., ZISER, K., FRIEDERICH, H. C., DE ZWAAN, M., LOWE, B., DINKEL, A., HERPERTZ, S., BURGMER, M., TAGAY, S., ROTHERMUND, E., ZEECK, A., HERZOG, W. \& ZIPFEL, S. 2019. The importance of body image disturbances for the outcome of outpatient psychotherapy in patients with anorexia nervosa: Results of the ANTOP-study. Eur Eat Disord Rev, 27, 49-58.

KAMMERS, M. P., DE VIGNEMONT, F., VERHAGEN, L. \& DIJKERMAN, H. C. 2009. The rubber hand illusion in action. Neuropsychologia, 47, 204-11.

KEIZER, A., ENGEL, M. M., BONEKAMP, J. \& VAN ELBURG, A. 2019. Hoop training: a pilot study assessing the effectiveness of a multisensory approach to treatment of body image disturbance in anorexia nervosa. Eat Weight Disord, 24, 953-958. 
KEIZER, A., SMEETS, M. A., DIJKERMAN, H. C., UZUNBAJAKAU, S. A., VAN ELBURG, A. \& POSTMA, A. 2013. Too fat to fit through the door: first evidence for disturbed body-scaled action in anorexia nervosa during locomotion. PLoS One, 8, e64602.

KEIZER, A., SMEETS, M. A., DIJKERMAN, H. C., VAN DEN HOUT, M., KLUGKIST, I., VAN ELBURG, A. \& POSTMA, A. 2011. Tactile body image disturbance in anorexia nervosa. Psychiatry Res, 190, 115-20.

KEIZER, A., SMEETS, M. A., DIJKERMAN, H. C., VAN ELBURG, A. \& POSTMA, A. 2012. Aberrant somatosensory perception in Anorexia Nervosa. Psychiatry Res, 200, 530-7.

KEIZER, A., SMEETS, M. A., POSTMA, A., VAN ELBURG, A. \& DIJKERMAN, H. C. 2014. Does the experience of ownership over a rubber hand change body size perception in anorexia nervosa patients? Neuropsychologia, 62, 26-37.

KEIZER, A., VAN ELBURG, A., HELMS, R. \& DIJKERMAN, H. C. 2016. A Virtual Reality Full Body Illusion Improves Body Image Disturbance in Anorexia Nervosa. PLoS One, 11, e0163921.

KHALSA, S. S., PORTNOFF, L. C., MCCURDY-MCKINNON, D. \& FEUSNER, J. D. 2017. What happens after treatment? A systematic review of relapse, remission, and recovery in anorexia nervosa. J Eat Disord, 5, 20.

KORNMEIER, J. \& BACH, M. 2012. Ambiguous figures - what happens in the brain when perception changes but not the stimulus. Front Hum Neurosci, 6, 51.

LAFER-SOUSA, R., HERMANN, K. L. \& CONWAY, B. R. 2015. Striking individual differences in color perception uncovered by 'the dress' photograph. Curr Biol, 25, R545-6.

LAUTENBACHER, S., ROSCHER, S., STRIAN, F., PIRKE, K. M. \& KRIEG, J. C. 1993. Theoretical and empirical considerations on the relation between 'body image', body scheme and somatosensation. $J$ Psychosom Res, 37, 447-54.

LONGO, M. R. 2015. Implicit and explicit body represenations. European Psychologist, 20, 6-15.

LONGO, M. R., AZANON, E. \& HAGGARD, P. 2010. More than skin deep: body representation beyond primary somatosensory cortex. Neuropsychologia, 48, 655-68.

LONGO, M. R. \& HAGGARD, P. 2010. An implicit body representation underlying human position sense. Proc Natl Acad Sci U S A, 107, 11727-32.

LONGO, M. R. \& HAGGARD, P. 2012. Implicit body representations and the conscious body image. Acta Psychol (Amst), 141, 164-8.

LOWE, B., ZIPFEL, S., BUCHHOLZ, C., DUPONT, Y., REAS, D. L. \& HERZOG, W. 2001. Long-term outcome of anorexia nervosa in a prospective 21-year follow-up study. Psychol Med, 31, 881-90.

MENG, M. \& TONG, F. 2004. Can attention selectively bias bistable perception? Differences between binocular rivalry and ambiguous figures. $J$ Vis, 4, 539-51.

METRAL, M., GUARDIA, D., BAUWENS, I., GUERRAZ, M., LAFARGUE, G., COTTENCIN, O. \& LUYAT, M. 2014. Painfully thin but locked inside a fatter body: abnormalities in both anticipation and execution of action in anorexia nervosa. BMC Res Notes, 7, 707.

MOLBERT, S. C., KLEIN, L., THALER, A., MOHLER, B. J., BROZZO, C., MARTUS, P., KARNATH, H. O., ZIPFEL, S. \& GIEL, K. E. 2017a. Depictive and metric body size estimation in anorexia nervosa and bulimia nervosa: A systematic review and meta-analysis. Clin Psychol Rev, 57, 21-31.

MOLBERT, S. C., THALER, A., MOHLER, B. J., STREUBER, S., ROMERO, J., BLACK, M. J., ZIPFEL, S., KARNATH, H. O. \& GIEL, K. E. 2017b. Assessing body image in anorexia nervosa using biometric self-avatars in virtual reality: Attitudinal components rather than visual body size estimation are distorted. Psychol Med, 1-12.

NICO, D., DAPRATI, E., NIGHOGHOSSIAN, N., CARRIER, E., DUHAMEL, J. R. \& SIRIGU, A. 2010. The role of the right parietal lobe in anorexia nervosa. Psychol Med, 40, 1531-9.

NOORDENBOS, G. \& ELBURG, A. V. (eds.) 2018. Handboek Eetstoornissen, Utrecht: De Tijdstroom.

PAILLARD, J. 1999. Body schema and body image: a double dissociation in deafferented patients. In: GAUTCHEV, G. N., MORI, S. \& MASSION, J. (eds.) Motor Control, Today and Tomorrow Sofia: Academic Publishing House.

PECK, T. C., SEINFELD, S., AGLIOTI, S. M. \& SLATER, M. 2013. Putting yourself in the skin of a black avatar reduces implicit racial bias. Conscious Cogn, 22, 779-87. 
PETKOVA, V. I. \& EHRSSON, H. H. 2008. If I were you: perceptual illusion of body swapping. PloS one, 3, e3832.

PIERLOOT, R. A. \& HOUBEN, M. E. 1978. Estimation of body dimensions in anorexia nervosa. Psychol Med, 8, 317-24.

PITRON, V., ALSMITH, A. \& DE VIGNEMONT, F. 2018. How do the body schema and the body image interact? Conscious Cogn, 65, 352-358.

PORRAS-GARCIA, B., SERRANO-TRONCOSO, E., CARULLA-ROIG, M., SOTO-USERA, P., FERRER-GARCIA, M., FIGUERAS-PUIGDERRAJOLS, N., YILMAZ, L., ONUR SEN, Y., SHOJAEIAN, N. \& GUTIERREZMALDONADO, J. 2020. Virtual Reality Body Exposure Therapy for Anorexia Nervosa. A Case Report With Follow-Up Results. Front Psychol, 11, 956.

PRESTON, C. \& EHRSSON, H. H. 2014. Illusory changes in body size modulate body satisfaction in a way that is related to non-clinical eating disorder psychopathology. PLoS One, 9, e85773.

PROBST, M., VAN COPPENOLLE, H., VANDEREYCKEN, W. \& MEERMANN, R. 1990. [Evaluation of body image perception in patients with anorexia nervosa]. Psychiatr Prax, 17, 115-20.

PROVENZANO, L., PORCIELLO, G., CICCARONE, S., LENGGENHAGER, B., TIERI, G., MARUCCI, M., DAZZI, F., LORIEDO, C. \& BUFALARI, I. 2019. Characterizing Body Image Distortion and Bodily SelfPlasticity in Anorexia Nervosa via Visuo-Tactile Stimulation in Virtual Reality. J Clin Med, 9.

RAEVUORI, A., KESKI-RAHKONEN, A. \& HOEK, H. W. 2014. A review of eating disorders in males. Curr Opin Psychiatry, 27, 426-30.

RIVA, G. 2016. Neurobiology of Anorexia Nervosa: Serotonin Dysfunctions Link Self-Starvation with Body Image Disturbances through an Impaired Body Memory. Front Hum Neurosci, 10, 600.

RIVA, G. \& GAUDIO, S. 2012. Allocentric lock in anorexia nervosa: new evidences from neuroimaging studies. Med Hypotheses, 79, 113-7.

RIVA, G. \& GAUDIO, S. 2018. Locked to a wrong body: Eating disorders as the outcome of a primary disturbance in multisensory body integration. Conscious Cogn, 59, 57-59.

ROCK, I. \& MITCHENER, K. 1992. Further evidence of failure of reversal of ambiguous figures by uninformed subjects. Perception, 21, 39-45.

SCHWOEBEL, J. \& COSLETT, H. B. 2005. Evidence for multiple, distinct representations of the human body. J Cogn Neurosci, 17, 543-53.

SERINO, A. \& HAGGARD, P. 2010. Touch and the body. Neurosci Biobehav Rev, 34, 224-36.

SERINO, S., POLLI, N. \& RIVA, G. 2019. From avatars to body swapping: The use of virtual reality for assessing and treating body-size distortion in individuals with anorexia. J Clin Psychol, 75, 313322.

SKRZYPEK, S., WEHMEIER, P. M. \& REMSCHMIDT, H. 2001. Body image assessment using body size estimation in recent studies on anorexia nervosa. A brief review. Eur Child Adolesc Psychiatry, 10, 215-21.

SLADE, P. D. 1985. A review of body-image studies in anorexia nervosa and bulimia nervosa. J Psychiatr Res, 19, 255-65.

SLADE, P. D. \& RUSSELL, G. F. 1973. Awareness of body dimensions in anorexia nervosa: cross-sectional and longitudinal studies. Psychol Med, 3, 188-99.

SLATER, M., SPANLANG, B., SANCHEZ-VIVES, M. V. \& BLANKE, O. 2010. First person experience of body transfer in virtual reality. PLoS One, 5, e10564.

SMEETS, M. A. 1995. Body size estimation research in anorexia nervosa. Breaking the deadlock. Utrecht: ISOR.

SMEETS, M. A. 1997. The rise and fall of body size estimation research in anorexia nervosa: A review and reconceptualization. European Eating Disorders Review, 5, 75-95.

SMEETS, M. A., INGLEBY, J. D., HOEK, H. W. \& PANHUYSEN, G. E. 1999. Body size perception in anorexia nervosa: a signal detection approach. J Psychosom Res, 46, 465-77.

SMEETS, M. A., KLUGKIST, I. G., ROODEN, S., ANEMA, H. A. \& POSTMA, A. 2009. Mental body distance comparison: a tool for assessing clinical disturbances in visual body image. Acta Psychol (Amst), 132, 157-65. 
SMEETS, M. A., SMIT, F., PANHUYSEN, G. E. \& INGLEBY, J. D. 1997. The influence of methodological differences on the outcome of body size estimation studies in anorexia nervosa. $\mathrm{Br} J \mathrm{Clin}$ Psychol, 36 ( Pt 2), 263-77.

SPITONI, G. F., SERINO, A., COTUGNO, A., MANCINI, F., ANTONUCCI, G. \& PIZZAMIGLIO, L. 2015. The two dimensions of the body representation in women suffering from Anorexia Nervosa. Psychiatry Res, 230, 181-8.

STEFANUCCI, J. K., PROFFITT, D. R., CLORE, G. L. \& PAREKH, N. 2008. Skating down a steeper slope: fear influences the perception of geographical slant. Perception, 37, 321-3.

STEINHAUSEN, H. C. 2002. The outcome of anorexia nervosa in the 20th century. Am J Psychiatry, 159, 1284-93.

SULLIVAN, P. F. 1995. Mortality in anorexia nervosa. Am J Psychiatry, 152, 1073-4.

TAYLOR-CLARKE, M., JACOBSEN, P. \& HAGGARD, P. 2004. Keeping the world a constant size: object constancy in human touch. Nat Neurosci, 7, 219-20.

TEACHMAN, B. A., STEFANUCCI, J. K., CLERKIN, E. M., CODY, M. W. \& PROFFITT, D. R. 2008. A new mode of fear expression: perceptual bias in height fear. Emotion, 8, 296-301.

TREASURE, J., WHITAKER, W., TODD, G. \& WHITNEY, J. 2012. A description of multiple family workshops for carers of people with anorexia nervosa. Eur Eat Disord Rev, 20, e17-22.

VAN SON, G. E., VAN HOEKEN, D., BARTELDS, A. I., VAN FURTH, E. F. \& HOEK, H. W. 2006. Time trends in the incidence of eating disorders: a primary care study in the Netherlands. Int J Eat Disord, 39, 565-9.

VASEY, M. W., VILENSKY, M. R., HEATH, J. H., HARBAUGH, C. N., BUfFINGTON, A. G. \& FAZIO, R. H. 2012. It was as big as my head, I swear! Biased spider size estimation in spider phobia. J Anxiety Disord, 26, 20-4.

WAGNER, A., RUF, M., BRAUS, D. F. \& SCHMIDT, M. H. 2003. Neuronal activity changes and body image distortion in anorexia nervosa. Neuroreport, 14, 2193-7.

WARREN, W. H., JR. \& WHANG, S. 1987. Visual guidance of walking through apertures: body-scaled information for affordances. J Exp Psychol Hum Percept Perform, 13, 371-83.

WILMUT, K. \& BARNETT, A. L. 2010. Locomotor adjustments when navigating through apertures. Hum Mov Sci, 29, 289-98.

YASUDA, M., WAGMAN, J. B. \& HIGUCHI, T. 2014. Can perception of aperture passability be improved immediately after practice in actual passage? Dissociation between walking and wheelchair use. Exp Brain Res, 232, 753-64.

ZIPFEL, S., GIEL, K. E., BULIK, C. M., HAY, P. \& SCHMIDT, U. 2015. Anorexia nervosa: aetiology, assessment, and treatment. Lancet Psychiatry, 2, 1099-111. 